\title{
Review
}

\section{Microtubule dynamics in plants}

\author{
Valya N. Vassileva ${ }^{1}$, Yuka Fujii ${ }^{2}$, Robert W. Ridge ${ }^{2 *}$ \\ ${ }^{1}$ Academic Metodi Popov Institute of Plant Physiology, Bulgarian Academy of Sciences, Academic Georgi Bonchev \\ Street, Block 21, 1113 Sofia, Bulgaria; ${ }^{2}$ Biology Department, Division of Natural Sciences, International Christian \\ University, Mitaka, Tokyo 181-8585, Japan \\ *E-mail: rwr@icu.ac.jp
}

Received June 20, 2005; accepted July 4, 2005 (Edited by M. Katsumi)

\begin{abstract}
Plant cells form a highly dynamic microtubule network organized into different arrays that are essential for many important cellular activities. A key feature of microtubules is their dynamic behaviour in which individual microtubules stochastically switch between periods of growth and disassembly. This feature contributes substantially to the rapid reorganization of the microtubule system in response to environmental and developmental stimuli. In this review we highlight recent developments on the dynamic behaviour of microtubules in plant cells and discuss some of the mechanisms responsible for the regulation of microtubule turnover. We also include an outline of the contribution of the dynamics toward the overall arrangement of the plant microtubule network. Special attention is given to the spatiotemporal changes in the microtubule configuration and dynamics during the establishment of the relationships between plants and other organisms.
\end{abstract}

Key words: Microtubules, mycorrhizal fungi, pathogenesis, symbiosis.

Microtubules are polarized polymers of $\alpha$ - and $\beta$-tubulin heterodimers, which are involved in the control of various aspects of plant morphogenesis and development, including cell division, intracellular transport, organization and motility. Plant microtubules are arranged into four different basic structures-the cortical interphase array, the preprophase band (PPB), the phragmoplast, and the mitotic spindle; the first three are unique to plant cells. In addition, some interphase plant cells possess endoplasmic microtubules (Lloyd et al. 1987; Sieberer et al. 2002). Each of these structures has its own function that varies according to the particular stage of the cell cycle (Williamson 1991; Goddard et al. 1994; Dhonukshe et al. 2005).

\section{Microtubule polymerization and disassembly dynamics}

As in other eukaryotes, the specific functions of microtubules in plant cells are highly dependent on their dynamic behaviour, characterized by periods of growth by polymerization and shrinkage by depolymerization with stochastic transitions between these two phases. The transition from growth to disassembly phase is termed a 'catastrophe', and the transition from disassembly to growth phase, a 'rescue' (Walker et al. 1988). This complicated behaviour of microtubules in living cells, known as dynamic instability (first described by
Mitchison and Kirschner, 1984), is believed to be a function of the hydrolysis of GTP bound to $\beta$-tubulin. During microtubule polymerization, GTP-tubulin subunits add to the growing microtubule end with a following hydrolysis to GDP. As a result, the tip of the polymer only remains in GTP form, forming a stable (stabilising) GTP cap; the microtubule body is composed of GDP-tubulin. If hydrolysis exceeds the addition of GTP-tubulin, the microtubule loses its GTP-cap, undergoes a catastrophe and quickly depolymerizes (Walker et al. 1989). The relative rates of polymerization and depolymerization, combined with the catastrophe and rescue frequency, are termed basic dynamic instability parameters, and determine the nature of the microtubule network in the cell (Chan et al. 2003; Dhonukshe and Gadella 2003; Vos et al. 2003).

Another key feature of microtubules is their intrinsic structural polarity that arises from the head-to-tail association of $\alpha / \beta$ tubulin heterodimers in the microtubule lattice. As a consequence of this polarity, the rate at which polymerization and disassembly takes place at opposite microtubule ends is different. The end that grows and depolymerizes faster is known as the plus end, and the opposite more stable end is called the minus end (Figure 1). In most eukaryotes, the minus end is usually anchored at the microtubule-organizing centre (MTOC) where nucleation occurs (Figure 1, asterisks), whereas the plus end is free and displays dynamic 


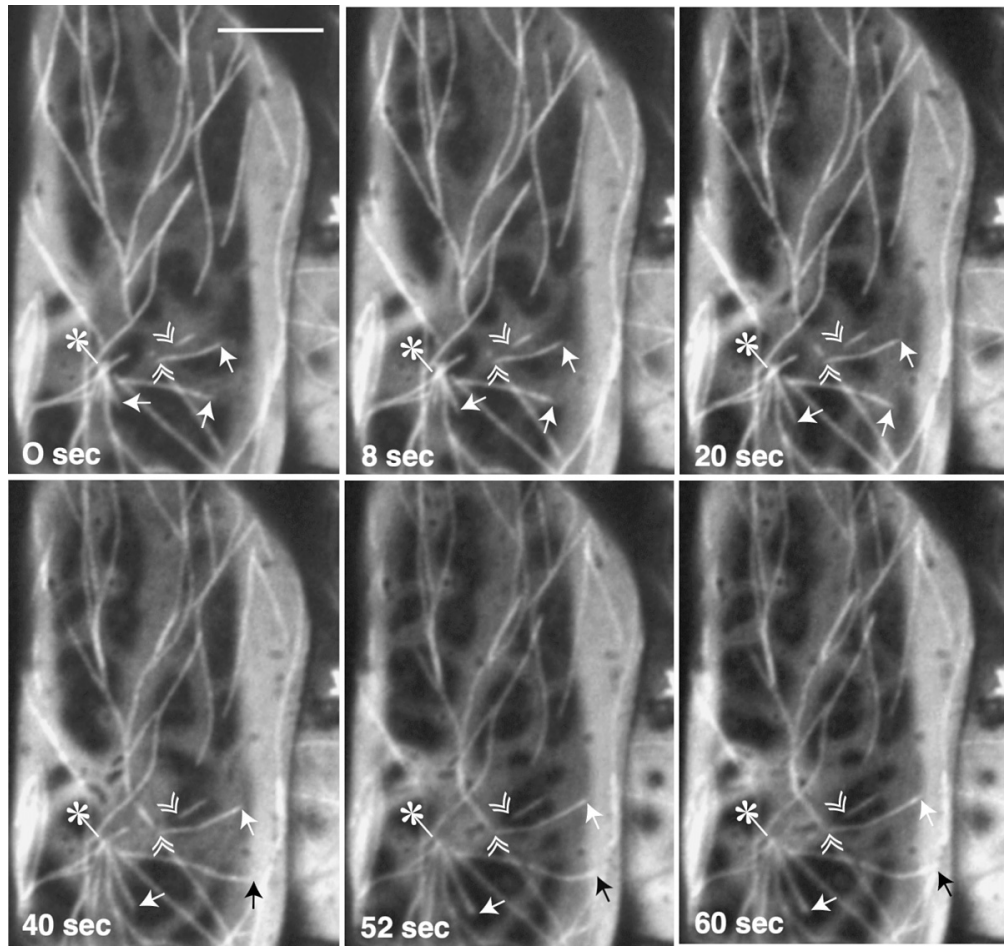

Figure 1. Time series of in vivo dynamic instability behaviour of cortical microtubules in root hairs of Lotus japonicus. Confocal laser images. Asterisks points to the site of microtubule nucleation, arrows - to growing plus ends of microtubules, double arrowheads show stable minus ends. $\mathrm{Bar}=3 \mu \mathrm{m}$. Unpublished data.

instability behaviour (Wade and Hyman 1997; Erhardt et al. 2002; Schmit 2002). This dynamic model was recently observed in root hairs of transgenic lines of Lotus japonicus, where the majority of the microtubules displayed stable minus ends and only plus polymer ends contributed to overall microtubule dynamicity (Figure 1; Vassileva et al. 2005). If the minus end is not anchored at the MTOC, the both microtubule ends exhibit growing and shortening events, a behaviour termed 'treadmilling' (originally termed by Margolis and Wilson, 1978). Treadmilling microtubules typically show addition of subunits to their plus end and loss of subunits from the opposite minus end. Unlike animal cells, higher plant cells do not possess centriole-based microtubule organizing centres; rather, microtubule nucleation in plant cells is related to the nuclear surface and multiple sites distributed throughout the cortex (Schmit 2002; Shaw et al. 2003; Dixit and Cyr 2004a). Shaw et al. (2003) have revealed that cortical microtubules in Arabidopsis plants are initiated at the cell cortex, after which they detach from the nucleation sites and undergo slow depolymerization at their minus ends. At the same time, the plus ends are dynamic and exhibit periods of growth and disassembly, resulting in sustained migration across the cortex by a 'hybrid treadmilling' mechanism. The coexistence of dynamic instability and treadmilling behaviour is also observed for microtubules in Arabidopsis root hairs, whose plus ends exhibit dynamic instability behaviour, while the opposite minus ends are stable or show slow depolymerization (Van Bruaene et al. 2004).

Early investigations of the mechanisms of microtubule dynamics through traditional immuno-cytochemical methods provide limited information, as they were performed on fixed cells and only static localization of the protein could obtained (Lloyd 1987; Goddard et al. 1994). Further experiments by microinjection of tubulin conjugated with fluorescent dyes, such as rhodamine or fluorescein, has allowed kinetic analysis of the microtubule network for up to several hours (Wymer et al. 1997; Himmelspach et al. 1999). The employment of GFP as a marker for exogenous gene expression has led to real-time observations of the dynamic behaviour of the plant cell cytoskeleton and has provided a powerful tool for a better understanding of its mechanisms (Haseloff and Amos 1995; Haseloff et al. 1997).

Generally, the dynamic organization of microtubules is achieved by polymerization of new microtubules, polymerization of existing microtubules to a new direction, microtubule reorientation, transport of microtubules to another position, and axial and lateral sliding of microtubules (Chan et al. 2003; Dhonukshe and Gadella 2003; Shaw et al. 2003; Vos et al. 2003). According to Shaw et al. (2003) the apparent microtubule dynamicity in Arabidopsis is a result mainly from polymerization and depolymerization at the 
microtubule ends and not from translocation of the intact microtubule polymer. Changing a particular parameter of individual microtubule dynamic instability drives the turnover kinetics of the microtubule population, and determines polymer increase or loss. Based on analysis of the basic parameters of dynamic instability obtained for microtubules in Arabidopsis hypocotyl cells, Shaw et al. (2003) measured an increase in the total polymer level. Other quantitative in vivo studies of plant microtubule dynamics displayed different dynamic instability parameters of microtubules during the cell cycle. Over the transition from interphase to PPB formation, the microtubule growth rate and catastrophe frequency doubles, but the shrinkage rate and rescue frequency remains constant, which makes microtubules shorter and more dynamic (Dhonukshe and Gadella 2003). Similarly, Vos et al. (2003) observed an increase of microtubule dynamics during PPB formation, related to the higher growth rates and higher frequency of catastrophe and rescue events. These changes, together with the relatively low microtubule dynamics in PPB (Hush et al. 1994), could explain the accumulation of microtubules to the forming PPB and their disappearance from the cortex by a "search-and-capture" mechanism (Vos et al. 2003). This mechanism allows translocation of the highly dynamic microtubule population to the forming PPB, and its possible stabilization through bundling or cross-linking of microtubules. Thus, the dynamic instability parameters of plant microtubules are important determinants of the transition of interphase microtubules to the PPB.

\section{Self-organization of microtubules and regulation of microtubule dynamics}

The stochastic dynamics of microtubules can be modified and regulated at many levels, by which their specific arrangement into ordered arrays is achieved. The self-organization processes in the microtubule population might be partly responsible for some modifications of its stochastic behaviour (Hashimoto 2003). Recent studies by Dixit and Cyr (2004b) demonstrated that dynamic turnover of cortical microtubules is modified by intermicrotubule interactions that occur when the growing microtubule plus ends encounter previously existing cortical microtubules. The outcome of these interactions depends on the angle at which microtubules encounter each other. Specifically, shallow-angle encounters promote microtubule coalignment and bundling, whereas steep-angle encounters promote microtubule disassembly. Based on these results, the authors propose that these simple intermicrotubule interactions define to a high extent the emergence of coaligned microtubule groups from a randomly arranged microtubule population.
In the direct regulation of cellular microtubule dynamics, a variety of proteins termed microtubuleassociated proteins (MAPs) (Hashimoto 2003; Van Damme et al. 2004) and their regulatory kinases and phosphatases (Sedbrook 2004) are involved. They usually bind to the microtubule lattice and influence microtubule behaviour during the cell cycle. Some of them have been identified to increase microtubule polymerization and stability by promoting bundling and cross-linking adjacent microtubules (Chan et al. 1999; Whittington et al. 2001; Yasuhara et al. 2002; Smertenko et al. 2004; Van Damme et al. 2004; Wicker-Planquart et al. 2004). This provokes a decrease in the frequency of microtubule catastrophe events (Caudron et al. 2000). Other MAPs function to destabilize and trigger the reorganization of microtubules (Dhonukshe et al. 2003; Gardiner et al. 2003). Thus, MAPs interact with microtubules, thereby affecting their dynamics, which leads to the control of microtubule length during different stages of the cell cycle (Hirokawa 1994; Desai and Mitchison 1997). In most cases, this is governed by the phosphorylation of MAPs that alters their affinity for microtubules. Phosphorylated MAPs are unable to bind to microtubules, which promotes microtubule disassembly (Hush et al. 1996). Treatment with inhibitors of protein phosphatases and kinases disorganizes cortical microtubules (Mizuno 1994; Baskin and Wilson 1997).

A wide range of environmental and developmental factors are known to affect the dynamics and architecture of microtubules in the cell (Desai and Mitchison 1997; Takemoto and Hardham 2004). Dynamic instability behaviour enables microtubules to be highly sensitive to light, gravity, exogenous forces, hormones, and toxicity (Williamson 1991; Ishida and Katsumi 1992; Nick 1998; Blancaflor 2002; Poschenrieder et al. 2004). Observations of gravity-induced changes of microtubules in epidermal cells of maize coleoptiles, injected with rhodamine-labeled tubulin, indicate that microtubules reorient from transverse to longitudinal by passing through a random phase before they align into increasingly parallel arrays (Himmelspach et al. 1999; Lloyd et al. 2000). From their in vivo studies, the authors conclude that the emergence of random microtubule arrays is a general feature of transition from transverse to longitudinal. Similar dynamic responses of microtubules to gravitropic stimulus were observed in hypocotyl cells of transgenic lines of $L$. japonicus stably expressing a fusion of green fluorescent protein and tubulin- $\alpha 6$ (GFP-TUA6) from $A$. thaliana (Ueda et al. 1999) (see Figure 2A-K, unpublished data). Analysis of microtubule dynamics in GFP-TUA6-labeled Lotus hypocotyl cells over a period of $10 \mathrm{~h}$ showed that horizontal placement of the hypocotyl triggered the reorientation of cortical microtubules from randomly 


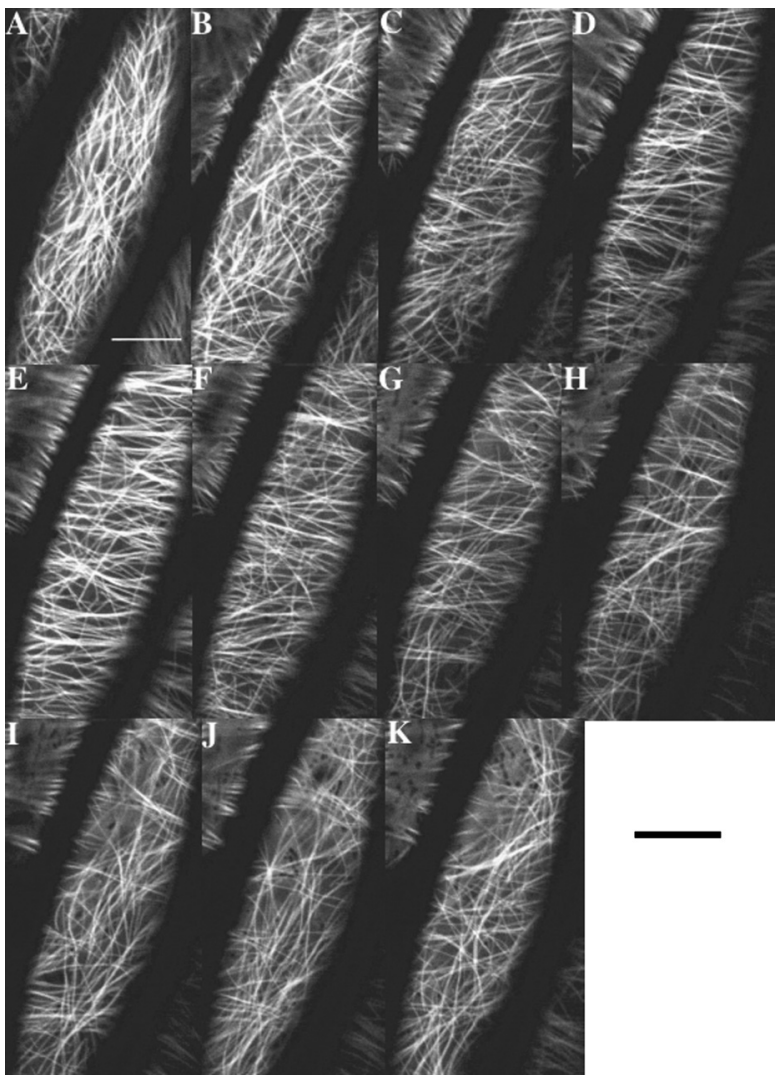

Figure 2. Gravity-induced microtubule reorientation in living Lotus japonicus hypocotyl cells. The plant was placed at 90 degrees to the gravity vector on a microscope stage. Confocal laser images were taken of the same hypocotyl cell at one hour intervals $(\mathrm{A}=0 \mathrm{~h})$. The majority of microtubules had clearly moved to transverse orientation by $3-4 \mathrm{~h}$ after induction (D, E), but gradually returned to random orientation by 9-10 h (J, K). Bar $=20 \mu \mathrm{m}$. Unpublished data.

organized patterns (Figure 2A, B) through a transitional stage with partly transverse (Figure $2 \mathrm{C}, \mathrm{D}$ ) to dominant transverse orientation by $4 \mathrm{~h}$ (Figure $2 \mathrm{E}$ and $2 \mathrm{~F}$ ), then microtubules began to reorient back toward transitional stage Figure 2G, H) to randomness Figure 2I-K). Two models have been proposed to explain how microtubules perceive and rearrange in response to gravity change (Himmelspach et al. 1999). The first is related to movement or sliding of individual microtubules, the second one includes selective stabilization or disassembly of microtubules based on the high microtubule dynamics. The overall reorientation process could include both models. Microtubule dynamic rearrangement during gravistimulation could merely be a response to the mechanical strain of bending (Hejnowicz et al. 2000). However, a study by Himmelspach and Nick (2001) revealed that gravity-induced microtubule reorientation in maize coleoptiles can be uncoupled from gravity bending. Preventing the upward bending and growth of coleoptiles by attaching them to microscope slides showed that growth inhibition without gravity stimulus does not provoke microtubules to reorient.
Therefore, microtubules could directly respond to gravity, and reorientation during gravity change is not simply a consequence of mechanical bending; microtubules are intracellular gravity sensors and transducers.

\section{Microtubule dynamics in plant-microbe interactions-pathogenesis and symbiosis}

The microtubular cytoskeleton is believed to play a prominent role in signal transduction and regulation of the relationships between plants and other organisms that could be potential pathogens or partners (Timmers et al. 1998; Blancaflor et al. 2001; Takemoto et al. 2003; Takemoto and Hardham 2004; Vassileva et al. 2005; Weerasinghe et al. 2005). The spatiotemporal changes in plant microtubule configuration and dynamics during fungal and oomycete pathogen penetration and during the establishment of mutualistic associations with mycorrhizal fungi and rhizobia are very complex and variable.

\section{Interactions with fungal and oomycete pathogens}

The response of the microtubule cytoskeleton to pathogen attack varies depending on the interacting species. Reorientation and loss of microtubules is observed in the early stages of the incompatible interaction of soybean hypocotyls with the specific pathogen Phytophthora sojae, but not with compatible interactions (Cahill et al. 2002). Moreover, treatment of hypocotyls with the microtubule depolymerizing agent oryzalin prior to inoculation does not alter the compatible response, but leads to breakdown of the incompatible response. To answer the question if there is a relationship between microtubule configuration and oomycete pathogen infection, Takemoto et al. (2003) visualized epidermal cell structure after attack by nonhost, incompatible and compatible oomycete pathogens in cotyledons of GFP-TUA6 labeled Arabidopsis plants. In some epidermal cells there is no visible change in microtubule organization, but in others, microtubules show a tendency for circumferential alignment around the penetration site. The most obvious change for the all three pathogen interactions is the appearance of strong but diffuse fluorescence around the site of infection. This type of fluorescence lasts throughout the whole period of observation (up to $36 \mathrm{~h}$ after inoculation) and could be explained by the presence of monomeric or dimeric GFP-tubulin forms. The accumulation of the GFP-tubulin subunits at the penetration site may due to increased tubulin synthesis, or to selective microtubule depolymerization. A number of studies have suggested that microtubule 
depolymerization provides a mechanism for the mobilization of the plant defense response against pathogen attacks (Kobayashi et al. 1994; Kobayashi et al. 1997; Binet et al. 2001). Although the precise biological significance of microtubule remodelling during pathogen infection is still poorly understood, the variable behaviour of microtubules during pathogen infection implies that the microtubule network is not directly involved in the defense response of plants.

\section{Interactions with mycorrhizal fungi and symbiotic bacteria}

Despite the miscellaneous information available on the plant microtubule behaviour during the establishment and progression of various mycorrhizal associations, there is no doubt that the microtubule cytoskeleton of both plant and fungal partners undergo dynamic changes (Matsubara et al. 1999; Timonen and Peterson 2002). The different categories of mycorrhizas are based primarily on the fungal partner in the association and the types of mycorrhizal structures formed. An important feature of mycorrhizas is the interface involved in nutrient exchange between the symbionts (Peterson and Massicotte 2004). The development of exchange interfaces in ectomycorrhizas, ectendomycorrhizas, and monotropoid mycorrhizas involve dramatic changes in the organization of microtubules (Kuga-Uetake et al. 2004). In arbuscular and orchid mycorrhizae, plant microtubules and actin microfilaments depolymerize almost completely in the plant cell cortex, and polymerize close to the surface of the hyphal masses, trunk hyphae or arbuscules (Matsubara et al. 1999; Blancaflor et al. 2001; Armstrong and Peterson 2002; Takemoto and Hardham 2004). Genre and Bonfante (1998) have hypothesised that cytoskeleton reorganisation during the symbiosis may influence the nutrient exchanges between symbiotic partners by controlling the transport mechanisms related to membrane repositioning and cell wall deposition. The study by Ditengou et al. (2003) shows that hypaphorine, the major indolic alkaloid compound delivered from ectomycorrhizal fungus Pisolithus tinctorius upon formation of mycorrhiza with Eucalyptus roots, significantly affects microtubule arrangement in the elongated root hairs of the host plant. In the subapical region of hypaphorine-treated root hairs, a highly fluorescent patch of aggregated microtubules usually appears, possibly as a consequence of bundling of the actin filaments. It is proposed that this hypaphorineinduced aggregation of microtubules and actin filaments could stabilize the structure of cytoskeletal elements, which may hinder the vesicle delivery and release in root hairs necessary for their elongation. Since hypaphorine is an IAA antagonist, and restoration of hypaphorine- induced aggregation of actin filament can be obtained by exogenous IAA application, it is suggested that endogenous IAA is necessary to maintain normal arrangement of cytoskeletal elements in elongating root hairs. Exogenous auxin is also known to stimulate root hair elongation (Katsumi et al. 2000). On the other hand, the study by Sampson and Heath (2005), where microtubule dynamics and subunit distribution were analysed in a strain of Aspergillus nidulans expressing GFP $\alpha$-tubulin, suggest substantial independence between microtubules and hyphal tip growth. It was proposed that the population of dynamic apical microtubules enhance migration of the 'cytomatrix', thus ensuring that organelles and proteins maintain proximity to the constantly elongating hyphal tip (Sampson and Heath 2005).

Some reports show that in many ecto- and endomycorrhizal symbioses the level of plant tubulin expression and the contribution of plant $\alpha-, \beta$-, and $\gamma$ tubulins to the total protein pool are higher compared to those in uncolonized systems (Bonfante et al. 1996; Timonen et al. 1996; Timonen and Peterson 2002; Timonen and Smith 2005). The gene from Eucalyptus globulus, encoding an $\alpha$-tubulin (EgTubA1), shows enhanced expression under ectomycorrhiza colonization (Carnero Diaz et al. 1996). It was also observed that in transgenic tobacco roots, the promoter of the maize $\alpha$ tubulin gene Tub3a is specifically activated in mycorrhizal cells (Bonfante et al. 1996). However, whether the observed changes in microtubular gene expression are a cause or a consequence of mycorrhizal root morphogenesis still remains to be established.

Using a $\gamma$-tubulin antibody, Genre and Bonfante (1999) have revealed MTOCs along the nuclear envelope and along the host membrane that surrounds the plant/fungus interface (perifungal membrane) in tobacco arbuscular mycorrhizas. The $\gamma$-tubulin is a microtubulenucleating protein localized basically in MTOCs (Shimamura et al. 2004). Its presence at the perifungal membrane implies microtubule nucleation there.

During the establishment of the symbiotic association of legume plants with rhizobia, the microtubule cytoskeleton assists in the infection process, as well as in the differentiation and maintenance of root nodules (Ridge 1992; Timmers et al. 1998; Timmers et al. 1999; Catoira et al. 2001; Weerasinghe et al. 2003; Weerasinghe et al. 2005). Generally, microtubules are abundant at the site of infection thread initiation and surround the infection thread during its development (Ridge and Rolfe 1985). They connect the host cell nucleus to both the root hair tip and the growing infection thread tip and maintain it in a subapical position (Timmers et al. 1999; Sieberer et al. 2002; Takemoto and Hardham 2004). An immunochemistry study showed that application of Rhizobium meliloti Nod 
factors caused rapid and dynamic changes in the pattern of microtubules in root hairs of Medicago sativa (Weerasinghe et al. 2003). The authors have observed a transient depolymerization of microtubular cytoskeleton and recovery thereafter in response to inoculation with purified R. meliloti Nod factors. Newly infected cells of Pisum sativum contain randomly oriented fragmented cortical and cytoplasmic microtubules exhibiting diffuse fluorescence (Davidson and Newcomb 2001). When the infected cells are fully developed, an extensive network of long cortical microtubules with random orientation and some parallel bundles is formed. The same authors assume that the cortical microtubules may be responsible for maintaining mitochondria and plastids in the periphery of nodule cells.

A recent study has revealed in details in vivo microtubule behaviour during the establishment and progression of the Rhizobium-legume symbiosis (Vassileva et al. 2005). Time-lapse confocal imaging of transgenic lines of the model legume L. japonicus that stably express a GFP-TUA6, has shown that the introduction of Mesorhizobium loti Nod factors directly affects some of the parameters of microtubule dynamic instability in root hairs, and thus, overall microtubule dynamics. In emerging and growing root hairs, the inoculation lowers microtubule polymerization rates by more than $45 \%$ and the frequency of rescue events about $60 \%$, so that cortical microtubules become less dynamic at a specific time after symbiotic inoculation. The first visible response to inoculation are root hair deformations that occur mainly in the most infectible zone containing emerging and growing root hairs. Since these deformations usually follow the Nod factor-induced decrease in microtubule dynamics, it is possible that the less dynamic cortical microtubules are prerequisite for the change of the growth polarity of root hairs. The visualization of microtubule arrangement after application of purified M. loti Nod factors reveals an increase in the population of the short microtubules with a larger deviation from the main root hair axis compared to the controls (Figure 3). Quantification of the microtubule length and organization at defined distances from the root hair tip shows that in the base part of the growing root hairs, the length of microtubules is reduced significantly and their axial orientation is replaced by random orientation (Vassileva et al. 2005). Weerasinghe et al. (2005) also dynamically profiled alterations in the cytoskeleton of living L. japonicus root hairs, which precede their deformation induced by $M$. loti Nod factors. They observed quick disintegration of the fine endoplasmic microtubules, followed by repolymerization from the very tip of the root hair, and increase of their number at 5-10 min. Cortical microtubules show a gradual increase in intensity and become more fragmented.
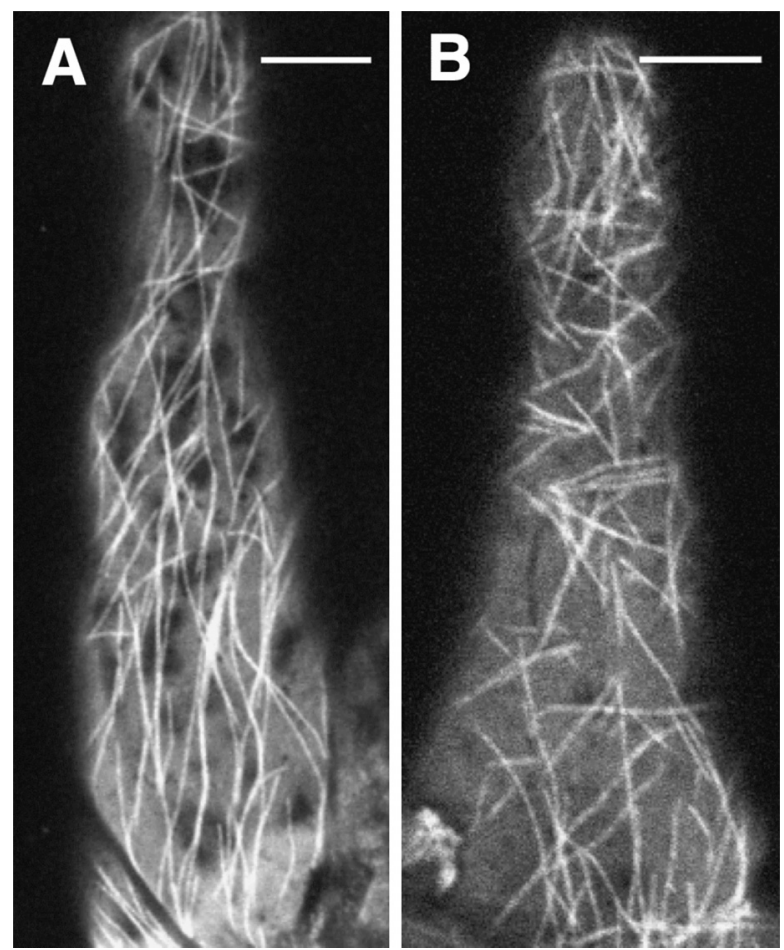

Figure 3. Cortical microtubule arrangement in growing root hairs of $L$. japonicus: A) control root hair cell; B) root hair cell inoculated with Mezorhizobium loti Nod factors. Confocal laser images. Bar $=8 \mu \mathrm{m}$. Unpublished data.

In summary, higher plant cells possess a very dynamic microtubule system that performs a variety of tasks during cell division and differentiation. This system also provides a mechanism by which plant cells can rapidly recognize any intracellular and extracellular signals, and respond to them by quick reorganization. In the last several years it has become clear that the microtubule system together with actin microfilaments are going to be major topics of research in studies of plant signal perception and transduction. Future studies should emphasize the accurate elucidation of the specialized features and functions of microtubule dynamics as a regulatory switch in different cellular processes, and how they themselves are affected by the resulting microtubule dynamics.

\section{References}

Armstrong L, Peterson RL (2002) The interface between the arbuscular mycorrhizal fungus Glomus intraradices and root cells of Panax quinquefolius: a Paris-type mycorrhizal association. Mycologia 94: 587-595

Baskin TI, Wilson JE (1997) Inhibitors of protein kinases and phosphatases alter root morphology and disorganize cortical microtubules. Plant Physiol 113: 493-502

Binet M-N, Humbert C, Lecourieux D, Vantard M, Pugin A (2001) Disruption of microtubular cytoskeleton induced by cryptogein, an elicitor of hypersensitive response in tobacco cells. Plant Physiol 125: 564-572

Blancaflor EB (2002) The cytoskeleton and gravitropism in higher 
plants. J Plant Growth Regul 21: 120-136

Blancaflor EB, Zhao L, Harrison MJ (2001) Microtubule organization in root cells of Medicago truncatula during development of an arbuscular mycorrhizal symbiosis with Glomus versiforme. Protoplasma 217: 154-165

Bonfante P, Bergero R, Uribe X, Romera C, Rigau J, Puigdoménech P (1996) Transcriptional activation of a maize $\alpha$ tubulin gene in mycorrhizal maize and transgenic tobacco plants. Plant J 9: 737-743

Breviario D, Nick P (2000) Plant tubulins: a melting pot for basic questions and promising applications. Trangen Res 9: 383-393

Cahill D, Rookes J, Michalczyk A, McDonald K, Drake A (2002) Microtubule dynamics in compatible and incompatible interactions of soybean hypocotyl cells with Phytophthora sojae. Plant Pathol 51: 629-640

Carnero Diaz E, Martin F, Tagu D (1996) Eucalypt $\alpha$-tubulin: cDNA cloning and increased level of transcripts in ectomycorrhizal root system. Plant Mol Biol 31: 905-910

Catoira R, Timmers ACJ, Maillet F, Galera C, Penmetsa RV, Cook D, Dénarié J, Gough C (2001) The HCL gene of Medicago truncatula controls Rhizobium-induced root hair curling. Development 128: 1507-1518

Caudron N, Valiron O, Usson Y, Valiron P, Job D (2000) A reassessement of the factors affecting microtubule assembly and disassembly in vitro. J Mol Biol 297: 211-220

Chan J, Calder GM, Doonan JH, Lloyd CW (2003) EB1 reveals mobile microtubule nucleation sites in Arabidopsis. Nat Cell Biol 5: 967-971

Chan J, Jensen CG, Jensen LCW, Bush M, Lloyd CW (1999) The $65-\mathrm{kDa}$ carrot microtubule-associated protein forms regularly arranged filamentous cross-bridges between microtubules. Proc Natl Acad Sci USA 96: 14931-14936

Davidson AL, Newcomb W (2001) Organization of microtubules in developing pea root nodule cells. Can J Bot 79: 777-786

Desai A, Mitchison TJ (1997) Microtubule polymerization dynamics. Annu Rev Cell Dev Biol 13: 83-117

Dhonukshe P, Gadella TWJ (2003) Alteration of microtubule dynamic instability during preprophase band formation revealed by yellow fluorescent protein-CLIP170 microtubule plus-end labeling. Plant Cell 15: 597-611

Dhonukshe P, Laxalt AM, Goedhart J, Gadella TWJ, Munnik T (2003) Phospholipase D activation correlates with microtubule reorganization in living plant cells. Plant Cell 15: 2666-2679

Dhonukshe P, Mathur J, Hulskamp M, Gadella TWJ (2005) Microtubule plus-ends reveal essential links between intracellular polarization and localized modulation of endocytosis during division-plane establishment in plant cells. BMC Biology 3: 11

Ditengou FA, Raudaskoski M, Lapeyrie F (2003) Hypaphorine, an indole-3-acetic acid antagonist delivered by the ectomycorrhizal fungus Pisolithus tinctorius, induces reorganisation of actin and the microtubule cytoskeleton in Eucalyptus globulus ssp bicostata root hairs. Planta 218: 217-225

Dixit R, Cyr R (2004a) The cortical microtubule array: from dynamics to organization. Plant Cell 16: 2546-2552

Dixit R, Cyr R (2004b) Encounters between dynamic cortical microtubules promote ordering of the cortical array through angle-dependent modifications of microtubule behaviour. Plant Cell 16: 3274-3284

Erhardt M, Stoppin-Mellet V, Campagne S, Canaday J, Mutterer J, Fabian T, Sauter M, Muller T, Peter C, Lambert AM, Schmit AC (2002) The plant Spc98p homologue colocalizes with gammatubulin at microtubule nucleation sites and is required for microtubule nucleation. J Cell Sci 115: 2423-2431

Gardiner J, Collings DA, Harper JDI, Marc J (2003) The effects of the phospholipase D-antagonist 1-butanol on seedling development and microtubule organisation in Arabidopsis. Plant Cell Physiol 44: 687-696

Genre A, Bonfante P (1998) Actin versus tubulin configuration in arbuscule-containing cells from mycorrhizal tobacco roots. New Phytol 140: 745-752

Genre A, Bonfante P (1999) Cytoskeleton-related proteins in tobacco mycorrhizal cells: gamma-tubulin and clathrin localisation. Eur J Histochem 43: 105-11

Goddard RH, Wick SM, Silflow CD, Snustad DP (1994) Microtubule components of the plant cell cytoskeleton. Plant Physiol 104: 1-6

Haseloff J, Amos B (1995) GFP in plants. Trends Genet 11: 328-329

Haseloff J, Siemering KR, Prasher DC, Hodge S (1997) Removal of a cryptic intron and subcellular localization of green fluorescent protein are required to mark transgenic Arabidopsis plants brightly. Proc Natl Acad Sci USA 94: 2122-2127

Hashimoto T (2003) Dynamics and regulation of plant interphase microtubules: a comparative view. Curr Opin Cell Biol 6: $568-576$

Hejnowicz Z, Rusin A, Rusin T (2000) Tensile tissue stress affects the orientation of cortical microtubules in the epidermis of sunflower hypocotyl. J Plant Growth Regul 19: 31-44

Himmelspach R, Nick P (2001) Gravitropic microtubule reorientation can be uncoupled from growth. Planta 212: 184189

Himmelspach R, Wymer CLL, Lloyd CW, Nick P (1999) Gravityinduced reorientation of cortical microtubules observed in vivo. Plant J 18: 449-453

Hirokawa N (1994) Microtubule organization and dynamics dependent on microtubule-associated proteins. Curr Opin Cell Biol 6: 74-81

Hush JM, Wadsworth P, Callaham DA, Hepler PK (1994) Quantification of microtubule dynamics in living plant cells using fluorescence redistribution after photobleaching. J Cell Sci 107: 775-784

Hush JM, Wu L, John PCL, Hepler LH, Hepler PK (1996) Plant mitosis promoting factor disassembles the microtubule preprophase band and accelerates prophase progression in Trandescantia. Cell Biol Int 20: 275-287

Ishida K, Katsumi M (1992) Effect of gibberellin and abscissic acid on the cortical microtubule orientation in hypocotyl cells of light-grown cucumber seedlings. Int J Plant Sci 153: 155-163

Katsumi M, Izumo M, Ridge RW (2000) Hormonal control of root hair growth and development. In: Ridge RW, Emons AMC (ed) Root Hairs Cell and Molecular Biology. Springer-Verlag, Tokyo, pp. 101-114

Kobayashi I, Kobayashi Y, Hardham AR (1994) Dynamic reorganization of microtubules and microfilaments in flax cells during the resistance response to flax rust infection. Planta 195: 237-247

Kobayashi Y, Kobayashi I, Funaki Y, Fujimoto S, Takemoto T, Kunoh H (1997) Dynamic reorganization of microfilaments and microtubules is necessary for the expression of non-host resistance in barley coleoptile cells. Plant $J$ 11: 525-537

Kuga-Uetake Y, Purich M, Massicotte HB, Peterson RL (2004) Host microtubules in the Hartig net region of ectomycorrhizas, ectendomycorrhizas, and monotropoid mycorrhizas. Can J Bot 82: 938-946

Lloyd CW (1987) The plant cytoskeleton: the impact of fluorescence microscopy. Annu Rev Plant Physiol 38: 119-139

Lloyd CW, Himmelspach R, Nick P, Wymer C (2000) Cortical microtubules form a dynamic mechanism that helps regulate the direction of plant growth. Gravit Space Biol Bull 13: 59-65 
Margolis RL, Wilson L (1978) Opposite end assembly and disassembly of microtubules at steady-state in vitro. Cell 13: $1-8$

Matsubara Y, Uetake Y, Peterson RL (1999) Entry and colonization of Asparagus officinalis roots by arbuscular mycorrhizal fungi with emphasis on changes in host microtubules. Can J Bot 77: 1159-1167

Mitchison T, Kirschner M (1984) Dynamic instability of microtubule growth. Nature 312: 237-242

Mizuno K (1994) Inhibition of gibberellin-induced elongation, reorientation of cortical microtubules and change of isoform of tubulin in epicotyl segments of azuki bean by protein kinase inhibitors. Plant Cell Physiol 35: 1149-1157

Nick P (1998) Signaling to the microtubular cytoskeleton in plants. Int Rev Cytol 184: 33-80

Peterson RL, Massicotte HB (2004) Exploring structural definitions of mycorrhizas, with emphasis on nutrient-exchange interfaces. Can J Bot 82: 1074-1088

Poschenrieder C, Doncheva S, Sonbol F, Amenos M, Riguu, Barcelo J (2004) Microtubule organization but not $\alpha$ Tubl and $\alpha T u b 3$ expression are primary targets of aluminum toxicity in maize root tips. In: Martins-Loucao MA, Cruz C (eds) Nutricao Mineral: Causas e consequencias da Dependencia da Fertilizacao. FCUL, Centro de Ecologia e Biologia Vegetal, pp 5-9

Ridge RW (1992) A model of legume root hair growth and Rhizobium infection. Symbiosis 14: 359-373

Ridge RW, Rolfe BG (1985) Rhizobium sp. degradation of legume root hair cell wall at the site of infection thread origin. Appl Environ Microbiol 50: 717-720

Sampson K, Heath IB (2005) The dynamic behaviour of microtubules and their contributions to hyphal tip growth in Aspergillus nidulans. Microbiology 151: 1543-1555

Schmit AC (2002) Acentrosomal microtubule nucleation in higher plants. Int Rev Cytol 220: 257-89

Sedbrook JC (2004) MAPs in plant cells: delineating microtubule growth dynamics and organization. Curr Opin Plant Biol 7: $632-640$

Shaw SL, Kamyar R, Ehrhardt DW (2003) Sustained microtubule treadmilling in Arabidopsis cortical arrays. Science 300: 17151718

Shimamura M, Brown RC, Lemmon BE, Akashi T, Mizuno K, Nishihara N, Tomizawa K-I, Yoshimoto K, Deguchi H, Hosoya H, Horio T, Mineyuki Y (2004) $\gamma$-tubulin in basal land plants: characterization, localization, and implication in the evolution of acentriolar microtubule organizing centers. Plant Cell 16: 4559

Sieberer BJ, Timmers ACJ, Lhuissier FGP, Emons AMC (2002) Endoplasmic microtubules configure the subapical cytoplasm and are required for fast growth of Medicago truncatula root hairs. Plant Physiol 130: 977-988

Smertenko AP, Chang H-Y, Wagner V, Kaloriti D, Fenyk S, Sonobe S, Lloyd C, Hauser M-T, Hussey PJ (2004) The Arabidopsis microtubule-associated protein AtMAP65-1: Molecular analysis of its microtubule bundling activity. Plant Cell 16: 2035-2047

Takemoto D, Hardham AR (2004) The cytoskeleton as a regulator and target of biotic interactions in plants. Plant Physiol 136: 3864-3876

Takemoto D, Jones DA, Hardham AR (2003) GFP-tagging of cell components reveals the dynamics of subcellular re-organization in response to infection of Arabidopsis by oomycete pathogens. Plant J 33: 775-792

Timmers ACJ, Auriac M-C, de Billy F, Truchet G (1998) Nod factor internalization and microtubular cytoskeleton changes occur concomitantly during nodule differentiation in alfalfa.
Development 125: 339-349

Timmers ACJ, Auriac M-C, Truchet G (1999) Refined analysis of early symbiotic steps of the Rhizobium-Medicago interaction in relationship with microtubular cytoskeleton rearrangements. Development 126: 3617-3628

Timonen S, Peterson RL (2002) Cytoskeleton in mycorrhizal symbiosis. Plant Soil 244: 199-210

Timonen S, Smith SE (2005) Effect of the arbuscular mycorrhizal fungus Glomus intraradices on expression of cytoskeletal proteins in tomato roots. Can J Bot 83: 176-182

Timonen S, Soderstrom B, Raudaskoski M (1996) Dynamics of cytoskeletal proteins in developing pine ectomycorrhiza. Mycorrhiza 6: 423-429

Ueda K, Matsuyama T, Hashimoto T (1999) Visualization of microtubules in living cells of transgenic Arabidopsis thaliana. Protoplasma 206: 201-206

Van Bruaene N, Joss G, Van Oostveldt P (2004) Reorganization and in vivo dynamics of microtubules during Arabidopsis root hair development. Plant Physiol 136: 3905-3919

Van Damme D, Van Poucke K, Boutant E, Ritzenthaler C, Inze D, Geelen D (2004) In vivo dynamics and differential microtubulebinding activities of MAP65 proteins. Plant Physiol 136: 3956-3967

Vassileva VN, Kouchi H, Ridge RW (2005) Microtubule dynamics in living root hairs: transient slowing by lipochitin oligosaccharide nodulation signals. Plant Cell 17: 1777-1787

Vos JW, Dogterom M, Emons AMC (2003) Microtubule become more dynamic but not shorter during preprophase band formation: a possible "search-and-capture" mechanism for microtubule translocation. Cell Motil Cytoskeleton 38: 278286

Wade RH, Hyman AA (1997) Microtubule structure and dynamics. Curr Opin Cell Biol 9: 12-17

Walker RA, Inoue S, Salmon ED (1989) Asymmetric behaviour of severed microtubule ends after ultraviolet-microbeam irradiation of individual microtubules in vitro. J Cell Biol 108: 931-37

Walker RA, O'Brien ET, Pryer NK, Soboeiro MF, Voter WA, Erickson HP, Salmon ED (1988) Dynamic instability of individual microtubules analyzed by video light microscopy: Rate constants and transition frequencies. J Cell Biol 107: $1437-1448$

Weerasinghe RR, Bird DMcK, Allen NS (2005) Root-knot nematodes and bacterial Nod factors elicit common signal transduction events in Lotus japonicus. Proc Natl Acad Sci USA 102: 3147-3152

Weerasinghe RR, Collings DA, Johannes E, Allen NS (2003) The distributional changes and role of microtubules in Nod factorchallenged Medicago sativa root hairs. Planta 218: 276-287

Whittington AT, Vugrek O, Wei KJ, Hasenbein NG, Sugimoto K, Rashbrooke MC, Wasteneys GO (2001) MOR1 is essential for organizing cortical microtubules in plants. Nature 411: 610613

Wicker-Planquart C, Stoppin-Mellet V, Blanchoin L, Vantard M (2004) Interactions of tobacco microtubule-associated protein MAP65-1b with microtubules. Plant J 39: 126-134

Williamson RE (1991) Orientation of cortical microtubules in interphase plant cells. Int Rev Cytol 129: 135-206

Wymer CL, Shaw PJ, Warn RM, Lloyd CW (1997) Microinjection of fluorescent tubulin into plant cells provides a representative picture of the cortical microtubule array. Plant J 12: 229-234

Yasuhara H, Muraoka M, Shogaki H, Mori H, Sonobe S (2002) TMBP200, a microtubule bundling polypeptide isolated from telophase tobacco BY-2 cells is a MOR1 homologue. Plant Cell Physiol 43: 595-60 